\title{
THE NATURAL ENVIRONMENT AS AN AGENT IN THE DESIGN AND OPERATION OF THE BOURNEMOUTH AIR FESTIVAL
}

\author{
DOROTHY FOX
}

The Faculty of Management, Bournemouth University, Dorset, UK

\begin{abstract}
There is a growing body of literature that discusses the protection of the natural environment in relation to events and festivals. However, there is little that demonstrates the value of nature to event stakeholders. This research contributes by recognizing the natural environment as an agent in the design and operation of the Bournemouth Air Festival, which is held on land, sea, and in the air. The case study was undertaken iteratively and within an inductive approach drawing on multiple sources of evidence, namely in-depth and unstructured interviews with stakeholders; observation and documentary evidence. In the absence of a theoretical proposition, the analytical strategy adopts a multidisciplinary approach to develop a case description. The study reveals first, the value of natural capital to the Festival and secondly, it develops a new model demonstrating the variability of the natural environment as an agent in the design and operation of the event. This shows that changes in the environment have occurred historically, recently, and even sometimes during the Festival. The latter create the greater challenges for the organizers as they may be consistent in their agency or inconsistent and further divide between those which are predictable, those which are foreseeable, and those which are unforeseeable. The article concludes with a discussion of the effect nature's actions have on event planning in its various forms and other implications for management.
\end{abstract}

Key words: Natural environment; Natural capital; Air festival; Outdoor events; Agency

\section{Introduction}

Events and festivals have had a long, historic relationship with nature, whether as a cause for worship or celebration, a space to locate the event, or simply a source of materials. Today, many events are still influenced by the natural environment, particularly those that take place in the open air, both in urban and rural areas. B. Jones et al. (2006) discussed three special events in Canada's National Capital Region: Winterlude based on the frozen Rideau Canal Skateway; the Canadian Tulip Festival; and the fireworks display of The Canada Day Celebrations. In contrast, Beer (2018) described the diversity of usually small rural events in the UK, focusing on farming, hunting, and equestrianism. 
These diverse examples confirm the importance of the natural environment to the event and festival industries and although the issue of the sustainability of natural resources is receiving growing attention, to date the natural and socionatural environment as a variable influence on events has not received the consideration it deserves. Rose and Carr (2018) suggested that "Most often in leisureoriented literature, nature takes the form of an inert, unproblematic backdrop" (p. 5). If this were the case, planning an outdoor event would be so much easier! But, as B. Jones et al. (2006) showed in relation to the three major Canadian events, the weather and climate are important factors contributing to event success or failure. However, this is just one example of the ways that the natural environment can impact on an event or be a critical resource and so this empirical study considers for the first time, the many influences the environment can have. The causes may be historic or contemporary, consistent or inconsistent, and positive as well as negative, but they all influence the event design and operations and hence have implications for management arising from them.

This research focuses on just one event to identify in detail the value of the natural environment, including some specific variations in that environment and the impacts these variations have. To consider the principal environments for outdoor events, the Bournemouth Air Festival (BAF) was selected. Bournemouth is a major tourism resort on the south coast of England and has a long tradition of air shows, with Britain's first International Aviation Meeting being held in July 1910 to celebrate the town's centenary (Rawlings, 2005). Even then the natural environment had an impact, when gusting winds contributed to Charles Rolls (of the RollsRoyce partnership) crashing his airplane (Ross, 2010).

This is an appropriate choice as the Chairman of the Safety Advisory Group (SAG) noted that "The venue is ... complicated in that it involves not only the land but also the sea and air. Each one of these elements has its particular potential difficulties" (Grant-Braham, 2013, p. 291).

Although this one event does not enable fully generalizable results, it does provide a basis for future research, into events located in all three different natural elements. Additionally, it is neither a mega-event nor a small event, so again the findings may be of value to a range of event organizers. In the absence of an existing theoretical basis, the case study drawing on multiple forms of evidence is undertaken iteratively and within an inductive approach to develop the case description and ultimately a conceptual framework.

To conclude, the aim of this study is to ascertain how the socionatural environment is an agent in the design and operation of the Bournemouth Air Festival. Its objectives are to first identify the actions of the environment in influencing the planning of the event and secondly to establish which actions are consistent and which vary and the impact this has on the planning and operational processes. Therefore, the next section discusses first, our relationship with the natural environment and secondly, some of the issues arising in the design and operations of events and festivals.

\section{Literature Review}

\section{Events and the Natural Environment}

Case (2013) defined the natural environment as: "that part of the earth's outdoor environment that exists independently of man. It thus includes the atmosphere, hydrosphere ... and the biosphere" (p. 13). However, he acknowledged that definition is "problematic." Nature can be perceived not only as a spatial and material location, as adopted in this study, but also as a construct or concept (Rose \& Carr, 2018). Additionally, the socionatural environment is often referred to and as Vickers (1981, p. 19) noted "Nearly all systems which include human beings are unstable and their instability is nearly always the unwilled result of man's actions."

Studies suggest that there are two prevailing and contemporary attitudes to nature, namely anthropocentrism and ecocentrism (Milfont \& Duckitt, 2010). Although, Holden (2008) acknowledged that: "It is unlikely that any kind of human action has a beneficial effect for the natural environment it interacts with, other than to protect or conserve it from more damaging forms of human behavior" (p. 97) - both attitudes may support environmental protection (Thompson \& Barton, 1994). The former does so because of the benefits the natural environment might provide for people, while the 
latter values nature intrinsically (Fennell \& Nowaczek, 2010; Kortenkamp \& Moore, 2001; Page \& Connell, 2009).

The natural environment is a key asset in the field of events and festivals and much has been written in these disciplines regarding protection of the environment (e.g., Case, 2013; Holmes et al., 2015; M. Jones, 2018). However, this approach is most likely to appeal to people of an ecocentric persuasion. Less research has been carried out that demonstrates the value of the environment to the industry. It is possible that if more work was undertaken in this area, policy makers, industrialists, and other stakeholders who hold anthropocentric attitudes would support greater environmental protection and hence contribute to more sustainable events and festivals. As the Department of Environment, Food and Rural Affairs (DEFRA) stated in a white paper in England in 2011, "When nature is undervalued, bad choices can be made" (p. 4). They went on to suggest that nature will be valued, by among others: "creating a green economy, in which economic growth and the health of our natural resources sustain each other, and markets, business and Government better reflect the value of nature" (DEFRA, 2011, p. 3). Fox (2012) argued that to achieve a successful transition to a green economy a more strategic approach to using natural capital needs to be adopted. Natural capital "directly or indirectly underpins value to people, including ecosystems, species, freshwater, soils, minerals, the air and oceans, as well as natural processes and functions" (Natural Capital Committee, 2019, p. 4).

Green infrastructure refers to the living network of land and water and other environmental features in urban as well as rural areas (DEFRA, 2011) and the services that these areas provide, whether directly or indirectly, include provisioning services such as food or water, regulating systems such as climate regulation or flood control and cultural services, such as recreational benefit, are often referred to as "ecosystem services" (DEFRA, 2014). Ecosystem services also include intangible benefits "including the inspiring beauty of our coasts and places for recreation and enjoyment" (DEFRA, 2011, p. 32). These services cannot be assigned any meaningful economic value but are nonetheless essential to the functioning of the planet and therefore need to be identified.
Previous research in the events sector has examined various interactions with the natural environment. Case (2015) divided these into two types, of which one is environmental outputs and the other is the inputs; these are the environmental resources in the supply chain used to deliver an event; for example, energy, materials, food and drink, etc. Therefore, topics include environmental protection whether from intended, unintended, or accidental impacts; sustainability (e.g., M. Jones, 2018); green events and festivals (e.g., Case, 2013); and events as proenvironmental learning spaces (e.g., Mair, 2014). These have all been examined before and so are not considered within the scope of this study.

In terms of those festivals and special events that take place in an outdoor space, the socionatural environment is used to varying degrees as a resource and as Case (2013) observed, this may involve modification of that environment. This can be through the actions of organizers and/or attendees or other stakeholders (Getz, 2012). Natural environments have mainly been studied from the perspective of the event participant or attendee (e.g., Pettersson \& Getz, 2009), whereas Gibson and Connell (2015) adopted the perspective of other stakeholders and assessed the impact of drought in relation to the role of festivals in Australian communities. The role of the organizer is also important (Getz, 2012) and B. Jones et al. (2006) described how the National Capital Commission of Canada have "implemented a diverse range of adaptive strategies to reduce the vulnerability" of their three events, in response to the negative impacts of the weather and climate variability from year to year. The weather is a key factor in any outdoor event and Getz (2002) showed that in a survey of predominantly North American International Festivals and Events Association professionals it was identified as the second most likely cause of festival failure (after a lack of corporate sponsorship).

\section{Design and Production of Events and Festivals in a Socionatural Environment}

Event design and production are two distinctly different processes (Bladen et al., 2012) with the latter delivering the conceptualization of the former. As part of the "experience economy" (Pine \& Gilmore, 1999), event design and production are 
key issues in the delivery of a successful event and can therefore be a high-risk element. Bladen et al. (2012) suggested a three-stage event design model, consisting of the concept and theme, the design, and the logistics. Design includes the significant role of creativity (Berridge, 2015; Getz, 2012), which can be both traditional (in the sense of reproducing previous iterations of an event) and innovative. Brown and James (2004) discussed five design principles: "scale, shape, focus, timing, and build," which have been added to with "emotion, meaning, authenticity, narrative and surprise" by Brown and Hutton (2013). The importance of the event experience is highlighted by Bertella (2014), who proposed a theory of design of embodied experiences based on the five senses. However, Orefice (2018) has subsequently shifted the perspective from experience creation to value creation using practice theory to help view "events and their design as subject to the influence of human and non-human actors" (p. 30). This study contributes to knowledge of this approach by incorporating the natural environment as the nonhuman actor.

Once designed, an event or festival has to be strategically planned and the logistical organization is sometimes referred to as "staging" (Ferdinand \& Williams, 2015) and concerns how services and goods are distributed before, during, and after an event. Therefore, it includes a range of operations, such as location selection and management, development of the site, and infrastructure installation. Accordingly, key factors include maximizing use of space, reducing congestion, and facilitating efficient movement (Tum et al., 2006). Therefore, this involves a number of stakeholders such as contractors, as well as the event organizers, in order to ensure not only an efficient operation but also, a quality attendee experience.

The selection of an event destination and setting are of primary importance for an event's success (Salem et al., 2014) and its sustainability (M. Jones, 2018) and can be strategic in terms of the commissioning body and involve political, economic, social, and environmental factors (Case, 2013). A mega-event such as the Olympic Games may be located based more on the former rather than the latter and is at the city or destination scale. The range of venues for outdoor events includes landbased sites such as agricultural land, parks, and mountains as well as water-based venues such as rivers, lakes, and coastal waters [e.g., Whale Day in Maui, described by Porter and Kaufmann (2013)]. Finally, the sky above may also be used (Fox, 2012). Getz (2012) suggested that: "The main initial considerations are location (e.g., centrality and accessibility), site characteristics (is it suitable for the event?), and the social-cultural context (has it historic and cultural meaning?)" (p. 226).

Following this first phase of strategic planning of an event, operational planning follows. These plans can vary in complexity and may include alternative operations where variations are known to regularly incur. B. Jones et al. (2006) suggested that this includes the timing of the event, the types of attractions offered, financial agreements, and contingency planning. Variations that are less likely are incorporated into contingency planning (Mallen, 2017). These back-up plans conceive potential deviations from the operational plans and ensure enhanced preparedness if they should occur. Finally, event emergency plans are developed, which can be in response to human-made or technological emergencies as well as natural ones (Silvers, 2012). For example, these include Emergency Action Plans (EAP) and Major Incident Plans (MIP).

To conclude, the existing literature relating to events and the natural environment considers the impact of the event on the environment, particularly in terms of sustainability, or acknowledges the natural environment as the location of the event, but to date a detailed analysis of the natural environment as an agent that influences the design and production of an event has not been undertaken.

\section{Methodology}

The following research questions have been developed:

1. What forms of agency does the natural environment have on the Festival?

2. How and when did this agency develop?

3. What positive benefits and opportunities does the agency offer and what negative impacts does the agency generate?

4. Is the agency consistent or if variable, is it predictable?

5. How can this this agency be integrated into the design and planning process? 
To answer these questions this study uses a single-case design (Yin, 2009) with the Festival employed as a revelatory case, not as Yin suggests because the situation has previously been inaccessible to scientific observation, but because it is newly recognized as important. Gerring (2017) argued that: "Case studies . . . may allow one to peer into the box of causality to the intermediate factors lying between some structural cause and its purported effect" (p. 248). To establish this causal inference the BAF is adopted as it is an effective choice because as Case (2013) noted, "Events take place on land, water and in the air" (p. 8) and the BAF is exceptional in using all three elements. The natural environment is constantly changing due not only to the earth's natural rhythms but also to individual occurrences, which may be entirely natural, partially natural, or entirely anthropogenic. In order to present as broad a picture as possible of the natural environment in relation to the BAF, this study considers all of the years that the Festival has existed since it began in 2009. The research is positioned within a constructivist paradigm and as will be demonstrated, is not only instrumental in that the BAF is a specific case from which general principles can be drawn, but is an expressive study, because it has some unique features that may or may not be generalizable to other contexts (Easterby-Smith et al., 2008). Ethical approval was obtained from the researcher's University together with the support of the Festival organizers.

Using an inductive approach, the study first employs secondary data sources drawing from the natural sciences, including geography, topography, geology, ecology, and meteorology, to describe the specific features of the event location and thereby provide a context for the agency of the natural environment. In order to be trustworthy a transparent display of multiple sources of evidence from both primary and secondary data sources is then used as follows. Documentary analysis of secondary data sources included webpages of the BAF, Red Arrows, and Bournemouth Daily Echo (the local commercial newspaper); print sources including Official Souvenir Programs; and thirdly The Bournemouth Air Festival 2009 video produced by Hallmark Productions.

Primary data were obtained from participant (attendee) and nonparticipant observation (Fox et al., 2014) undertaken at various times and days from the Wednesday set up to the Monday shut down over the period of the festivals in 2014, 2015, and 2016. During these times, fieldwork notes were written and photographs taken. The author has been a resident of Bournemouth for many years and has a comprehensive familiarity with the environment of the Festival. Secondly, semistructured interviews were carried out with two key participants: The Bournemouth Air Festival Director (BAFD) and the Head of Operations, Bournemouth Borough Council (HO). Thirdly, short, unstructured interviews were undertaken with a range of stakeholders, namely, the RAF Typhoon Display Manager; Festival volunteers including marshals; Bournemouth Lifeguard Corps (volunteers); local hoteliers and concession operators, etc.

Transcriptions were made of the recorded interviews and both the primary and secondary data were analyzed thematically (Fox et al., 2014). The coding process entailed several stages. First, the physical feature was identified (e.g., the beach), next the secondary data was used to describe the feature, and then, initial and pattern coding was used to identify when the natural feature occurred, whether it was consistent or inconsistent and if the latter, whether predictable or unforeseeable. Finally, the impact of the environmental agency on the event planning was identified. These plans were categorized as standard event plans, alternative event plans, contingency plans, and emergency plans, as discussed in the literature. Following several iterations of reading and coding, and revisions and reclassifications a conceptual model was developed (Bernard \& Ryan, 2010). This used the approach of identifying the key constructs and then showing the linkages between the constructs in a visual format.

\section{Findings}

\section{The Case: The Bournemouth Air Festival}

Adopting the framework of Goldblatt's (2005) 5 Ws (who, what, why, when, and where), the concept and theme of the Bournemouth Air Festival can be described. The event is held as part of an economic objective to use events to attract more visitors to the coastal resort (BAFD). The promotional line for the BAF is "By the Sea and Completely Free" (Sadd \& 
Gouthro, 2013). It is a free to access festival operating from 10am to $10 \mathrm{pm}$ over 4 days from Thursday to Sunday in late August each year. Since it began in 2008, the Festival has attracted over 8.5 million visitors and is acknowledged as one of the top 10 air shows in the world by USA Today, which stated that it "combines two great things: airplanes and the beach" (USA Today, 2013). A key attraction is the Red Arrows, or Royal Air Force Aerobatic Team, which "exist to demonstrate the professional excellence of the Royal Air Force and promote recruitment to the Royal Air Force" (Royal Air Force, 2017).

\section{The Festival Location}

The BAF location is a "Temporary venue in a highly managed landscape" (Case, 2013, p. 32) with a considerable degree of intervention, but over a relatively short period of time. Responsibility for the operational aspects lies with a core team of four within the Council Events Group (Sadd \& Gouthro, 2013). As the HO acknowledged, it is not the best site logistically - an airfield would be much easier, but that would not have the attraction and accessibility, etc. The main coach and train station are a short distance from the Festival site, which is easily accessible by foot or bicycle. Visitors also sail from the nearby harbors of Poole, Christchurch, and Lymington and the port of Southampton by private or chartered boat.

As Figure 1 of Poole Bay shows, Bournemouth, on the south coast of the UK, is to the east of Poole Harbor, the second largest natural harbor in the world. The festival takes place on a stretch of coast between two Victorian piers, approximately 1.5 miles $(2.5 \mathrm{~km})$ apart, one at Bournemouth and the other at Boscombe to the east, an area, as noted above, which is famous for its recreational value (DEFRA, 2011). The aircraft elements can be viewed from the length of the Bay, which forms a natural amphitheater (BAFD). Between the sandy beach and the cliffs is a wide promenade and at the top of the cliffs there are gardens, a road, and then hotels, all running parallel to the sea.

\section{Planetary Position}

Although much of the remainder of the study concentrates on the natural environment at the local scale, the immensity and influence of the planet as

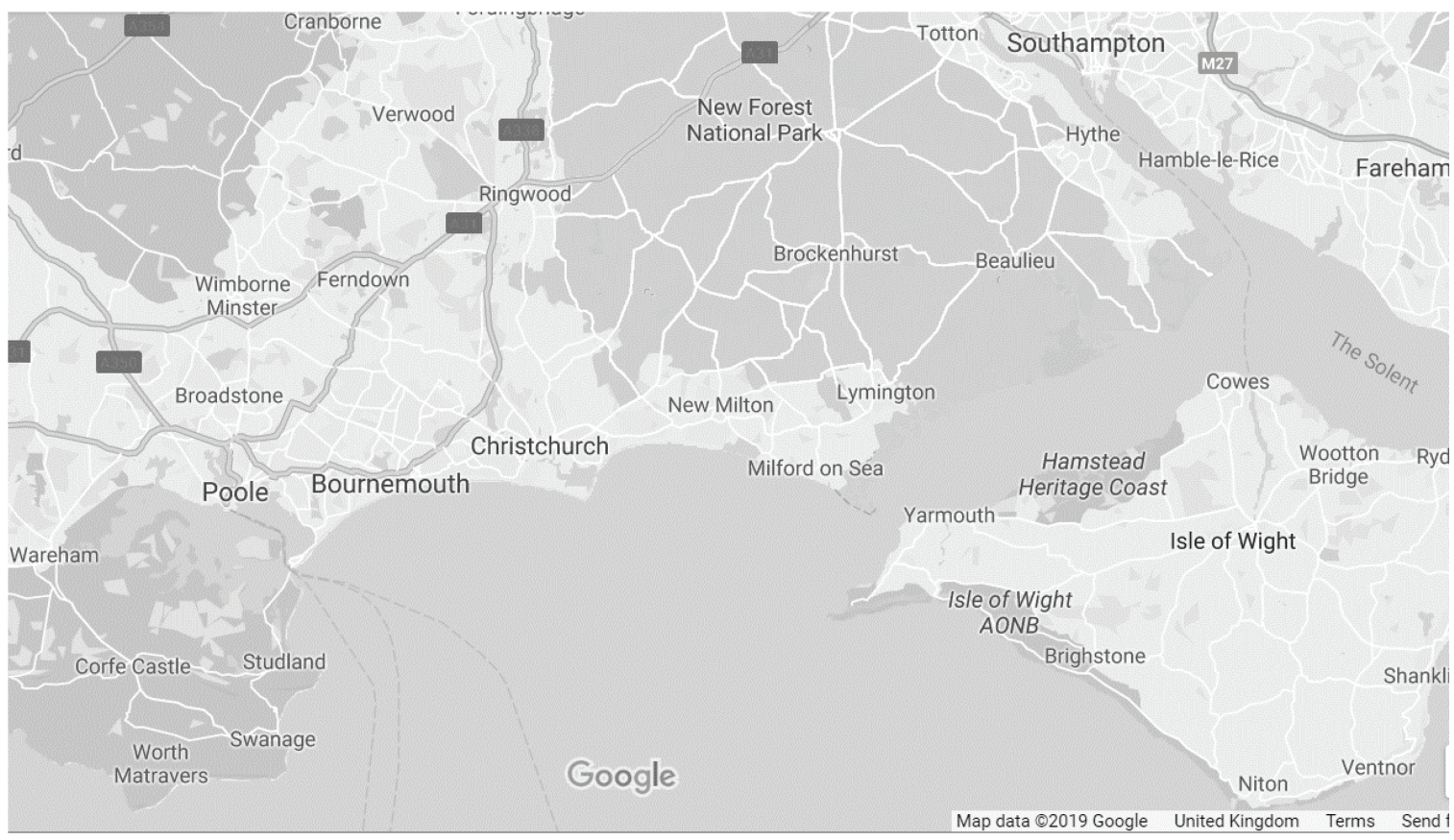

Figure 1. Map of Poole Bay (source: Google Maps, 2018). 
a whole should not be overlooked. Gravity, for instance, may be generally consistent and only vary geographically minutely, because the Earth is neither perfectly spherical nor uniformly dense (Hirt et al., 2013), but for the Red Arrow pilots it determines what they wear: "Without the help of an anti-' $g$ ' suit [an elasticized garment] the pilots would rapidly get tired and might even black out" (Royal Air Force, 2017). This effect is clearly predictable and therefore forms part of the standard planning for the event.

Important for all outdoor events is the event's location on the Earth as this determines the hours of daylight or night time. On the first day of the 2017 Festival in Bournemouth, Thursday the 31st of August, the sun rose $75^{\circ}$ east at 06.20 am and set at $284^{\circ}$ west at $19.54 \mathrm{pm}$. Likewise, moonrise was at $122^{\circ}$ southeast at $16.24 \mathrm{pm}$ and moonset was at $239^{\circ}$ southwest at $00.32 \mathrm{am}$. This meant that there were $13 \mathrm{hr}$ and $34 \mathrm{~min}$ of daylight. This can decrease by over $5.5 \mathrm{hr}$ in winter and almost $3 \mathrm{hr}$ from the height of the summer (Timeanddate.com, 2017). Because events are a temporal phenomenon, the time at which an event is held both in terms of duration and the timing is important. For the BAF, the natural lighting has enabled a diverse program of events to be incorporated in the design. During the day, the Royal Air Force (RAF), Royal Navy, Army, and Royal Marines all participate, supplying a range of ships and aircraft. There are also civilian airplanes both modern and historic and an air balloon event. At sunset in 2016, The Band of Her Majesty's Royal Marines HMS Collingwood performed an evening concert and sunset ceremony (Royal Navy, 2016). Dusk has also been used to deliver displays with wingtip fireworks and smoke trails. Since 2011, the event continues after dark with "Night Air" incorporating concerts and other entertainments to add to the flying elements. Fireworks, which were initially only on the Saturday night in 2008 have subsequently been extended to 3 nights. As Evans (2015) noted, "reclaiming the night [can provide] an alternative and supplementary experience to the traditional night life of entertainment" (p. 428).

\section{The Seasons of the Year}

The changing lengths of the days and nights throughout the year are because the Earth is tilted $23.5^{\circ}$ on its axis of rotation and this tilt also determines seasonal variation (Amsel, 2017). At a latitude of $50.72^{\circ}$ north and a longitude of $1.88^{\circ}$ west (LatutudeLongtitude.org, 2018), Bournemouth has four different seasons, with the Festival taking place at the end of the summer season. For the Red Arrow pilots, the winter season enables the team to spend "the six months from October through to April practicing for the upcoming display season ... it takes all those months for each pilot to become thoroughly proficient at flying in his own position" (Royal Air Force, 2017).

Changes in normal weather patterns may be the result of natural phenomena, such as El Niño and La Niña (Scaife, 2010), but other variation may be a result of anthropogenic action causing climate change (Met Office, 2018a). Generally, Bournemouth has a temperate climate with the warmest months being July and August, ranging on average $12-22^{\circ} \mathrm{C}$ (Met Office, 2021). August, when the Festival is held, has fewer days of rainfall than any other month of the year (Met Office, 2017) and an average of $7.3 \mathrm{hr}$ of sunshine (The Beach Guide, 2017). However, within these averages, there is much day-to-day variability and the unpredictability of the weather in the UK means that like many outdoor venues which are affected by changes in the weather (Case, 2013), there has been considerable impact on the design and operation of the BAF. This is demonstrated through the variation in overall visitor numbers in the first 4 years of the Festival, which were 750,000 in 2008, then rose to 1.3 million in 2009 before falling back to 700,000 in 2010 , before again rising to 1.02 million the following year (estimates provided by BAFD). As Getz (2002) showed, the weather has been considered the second most important cause of why festivals may fail. However, this is planned for in Bournemouth, as the BAFD stated to the local paper after a particularly bad day of weather "that's why we have a 4-day show" (Daily Echo, 2015). For the pilots:

A decision on whether or not we fly will not be made until the last minute. We might even get into the craft or even airborne before a decision is made. We take each day as it comes. The weather is so changeable, it's difficult to predict. (Squadron leader Mike Ling, Red Arrows, during the Festival in 2016, BBC News, 2016) 
The following elements are typical of an English summer are therefore considered next: clouds, rain, wind, and sun.

The Red Arrows design their shows with the British weather in mind and adapt their display according to the cloud base. Their absolute lowest cloud base that they can fly at is $700 \mathrm{ft}$, which was forecast in 2016 and they therefore gave a flat display, whereas the previous day had been a rolling display (Daily Echo, 2016a). The differences in design are as follows:

There are three types of display the Team Leader can elect to fly-full, rolling, or flat. To carry out a full, looping, display the base of the cloud must be above 5,500ft to avoid the aircraft entering the cloud at the top of the loop. If the cloud base is less than $5,500 \mathrm{ft}$, but more than $2,500 \mathrm{ft}$, the team will perform the rolling display-substituting wing-overs and rolls for the loops. And when the cloud base is below $2,500 \mathrm{ft}$, the team will fly the flat display, consisting of a series of flypasts and steep turns. (Royal Air Force, 2017)

However, other display "planes have a higher minimum cloud base and on the Thursday in 2015, the Hawk team had to cancel for the first time in four years because they need a 1,000ft cloud base" (Daily Echo, 2015). The team leader of the RAF typhoon Display team, which will not fly with a cloud base of under $1500 \mathrm{ft}$, will take the decision on which display to undertake before he checks into his aircraft, but then may revise this upon arriving on site (RAF Typhoon Display Manager).

In 2016, heavy rain led to changes in the times of the air displays and the Red Arrows were reprogrammed. "In the meantime, the many food, craft and information stalls along the prom appear to be benefitting as people look for shelter from the damp" (BBC News, 2016). Rain has an effect on not only the air displays, but also many of the concessions. During the setup on Wednesday of the 2015 show, an operator described how he was changing light bulbs and "trying to get it done before the rain comes in." That same year a charity tent was busier on the Thursday in the rain than on the Friday, because they were open and had a porch, so that visitors could shelter out of the rain. The volunteer added that if it was raining as forecast on the Sunday, she would "go for breakfast to see how busy it gets before making a decision whether to open or shut down straight away." Several traders said they were busier when it is cloudy or poorer weather, because when it is hot and sunny, visitors "sit on the beach and don't move." Another "winner" when it was wet was the RAF charity stand who sold "loads and loads of umbrellas!" Similarly, an employee of the Oceanarium, a visitor attraction at the Pier, stated that they were really busy during the rain, but "dead today."

In 2011, there was such heavy rainfall that the Lower Gardens through which the Bourne Stream flows was flooded on the Thursday. This is a key evacuation route for the Festival, in case of an emergency and the Major Incident Planning had to be adapted accordingly at very short notice (HO). Visitors were also advised not to swim in the sea on that Thursday, because of the storm water, for 24 $\mathrm{hr}$ or two tides, but this was ignored by many visitors (Lifeguard). These descriptions illustrate the very varied ways in which the weather can have an impact - with some impacts being both positive for some stakeholders and negative for others.

\section{The Air}

The prevailing wind in Bournemouth is usually from the south west (Met Office, 2018b) and is therefore an onshore breeze, which is safer for sea users (Lifeguard) but it can vary from day to day. As Case (2013) noted, "High winds can disrupt many events" (p. 21), but even lighter winds can have an impact. During the setup on the Wednesday of the 2015 show, the breezy weather caused a sound technician to tie down materials on a scaffolding framework with plastic tie wraps to secure it to the frame. As the winds became more severe, a charity had to take down their marquee.

However, like the rain, wind can also have positive as well as negative effects. The display teams produce color vapor trails, which add a positive impact to the display sequences when watched by the visitors. These trials when photographed against a background of blue sky are also beneficial in another way-they are the most photographed aspect and hence a key marketing tool of the Festival. However, for the Red Arrows, "The primary reason that the team use visible vapor trails is that of flight safety. The trails allow the pilots to judge 
the wind speed and direction far more accurately than by any other means" (Royal Air Force, 2017).

\section{The Sea}

In the same way as the air above the earth's surface has many variable states; the sea too is constantly changing, which needs to be factored into the planning of the design and operations. As Case (2013) noted, tides and currents can affect events. "With the exception of their arrival maneuver, the Red Arrows do not fly directly over the crowd" (Royal Air Force, 2017), instead they display over the sea. But as the BAFD stated: "We have to consider what we call secondary crowd. The main type is water vessels watching the displays." Accordingly, marker buoys are set out to identify exclusion zones, where the small boats cannot enter, as in addition to the aerial displays there are also a number of Royal Navy and other ships each year. Numerous visitors attend the Festivals in small vessels, sailing out from the neighboring harbors of Christchurch and Poole. The narrow channel at Sandbanks at the entrance to Poole Harbor is about $370 \mathrm{~m}$ wide and on an average spring tide, over $36 \mathrm{~m}$ tons of water flows through in $3.5 \mathrm{hr}$ : "the force of the outflowing current may be better imagined than described. ... Most yachtsmen accustomed to use this harbor have had some such unpleasant experience and been compelled to drop anchor and await the turn of the tide" (Lock, 1948, p. 123). In 2009, there was a mass of small boats trying to enter through the Poole Harbor entrance at the same time - subsequently the program has been changed so that it does not finish with the Red Arrows on a Sunday, so that boats depart at various times, rather than all at once (HO).

The prevailing current is from the west to the east and so sand is carried along the shore. The wind and water also carry natural materials such as dislodged seaweed and anthropocentric debris onto the beaches. The $\mathrm{HO}$ explained that the Bay is fortunate in that less material comes ashore and has to be removed by the Local Authority than might be anticipated, because the headland at Swanage (see Fig. 1) causes it to be swept past. The beaches are cleaned early each morning with mechanical rubbish pickers on the sand-as the HO observed it would be cheaper on a grass field site, but they already have the equipment for the season.
Due to its geological history, including the inundation of the Solent River about 7,000 years ago, Poole Bay area is rare in that it has double tides which are an unusual phenomenon consisting of four high tides in a $24-\mathrm{hr}$ period:

\begin{abstract}
The ebb-tide current, which comes down the Solent is penned up by Swanage and Studland Bays, thus forming a head of water which, in turn, pens back the water flowing out from Poole Harbor. Accordingly, immediately upon the first high water, the tide ebbs from the harbor for an hour and a half. Then the accumulation of water in the bay outside causes it to turn and flow again for another hour and a half, making a second high tide three hours after the first. The main ebb then makes away for three hours and a half; after which the tide flows for six hours, and the cycle is repeated. (Lock, 1948, pp. 122-123)
\end{abstract}

These tides are reasonably predictable over the long term; however, during the Festival in 2016, the music band the Kaiser Chiefs had to be cancelled at Boscombe beach because higher than expected tides, combined with onshore winds, flooded the beach.

In Poole Bay, the swell is often high enough to afford surfing but on August 31, 2017 at $0.5 \mathrm{~m}$ it was much lower than many areas around the UK due to the topography providing a sheltered position. For the lifeguards, this means the crowds enjoying the Festival are much safer. However, the sea reaches its warmest between August and September - by way of example, on that same day, the sea temperature was $18^{\circ} \mathrm{C}\left(64^{\circ} \mathrm{F}\right)$ (The Beach Guide, 2017). Therefore, the foreshore-the area of beach between high and low water levels-is popular with adults and children to enjoy between the other activities that the Festival offers. However, this does create problems for the lifeguards, as in the warmer seas of August, the Weever Fish (Echiichthys vipera, lesser), which are about $10 \mathrm{~cm}$ long are common in the sandy shallows. "They are renowned for their toxic venom which is delivered by way of a spine on the dorsal fin when trodden on" (Thornton \& McGowan, 2010, pp. 194-195). They bury themselves in the sand to trap their prey of other small fish. The sting is extremely painful and can be dangerous and, if stung, bathers are advised to seek help from the lifeguards. 


\section{The Land}

The land mass is mainly south facing and consists of the beach, the promenade, the cliffs, the overcliff, and the hinterland. As noted above, the natural migration of sand is from west to east and this has necessitated "Dredging and the installation of groynes to preserve [the] beaches" (Case, 2013, p. 15). The sand also creates a buffer zone between the waves and the sea wall and other infrastructure. The resort is famous for its soft clean sands unlike the pebbles in other resorts further along the coast and the general width of the beach allows artificial roadways to be created for the Festival. There were a few minor issues for contractors in 2014 at high tide as the beach will need replenishing again in a few years. Also, one contractor setting up for the first time on sand observed that working on grass is much quicker and less tiring to walk on-"the sand's the worst stuff," he said, and that he needed to allow more time.

Between the beach and the cliffs there is a seawall and then an undercliff drive or tarmacadam pedestrianized promenade about $10 \mathrm{~m}$ across, which is lined with beach huts with their backs to the cliff face. During the Festival, about 1.5 miles of trading stalls and ground displays are located between the Bournemouth and Boscombe Piers and at Pier Approach. This long narrow strip creates limited access (HO); ingress is through Boscombe at the easterly end and there is then a one-way system along the relatively narrow promenade to egress at Bournemouth. Because of this, deliveries are limited to between 06:30 and 08:30 hr each morning and all vehicles must have left the site by 09:00 hr. Vehicles are permitted to return between 18:00 and 19:00 hr and/or finally each day from 22:45 to $23: 15$. This creates problems for the set up and shut down and for the commercial traders to replenish stock, as well as for the Local Authority to remove rubbish, etc. Similarly, the natural topography limits the availability of water, which is usually more accessible at other outdoor show areas. Caterers are warned in advance that there are:

Controlled flow "push" taps along the Seafront promenade (Undercliff drive). ... Due to the controlled flow this means that only small containers can be filled such as kettles, drinking bottles etc. If large amounts of drinking water are required, a charge will be made to connect to separate metered outputs which are only available along the Seafront promenade.

These examples demonstrate how the Festival organizers have developed plans and communicated them to other stakeholders to limit the impacts of these environmental features.

Bournemouth has extensive cliffs of goldenyellow sandstone that are generally in a natural state. They are highest at the eastern end, and the slope of the cliffs has been routinely regraded with progressive stabilization of the cliffs over recent decades. However, during the winter storms of 2014, "Tons of rock were dislodged at . . beaches along the south coast, such as . . Bournemouth" (Simons, 2014, p. 83). An old landslide on the cliff to the east of Bournemouth Pier provides a small passing space to the width of the promenade. This area allows space during the Festival for temporary storage for pedestrian fencing after it is unloaded and before it is placed in position. In contrast to this chance benefit, as with the water supply, the cliffs also are problematic for the provision of electricity for both the permanent traders and the temporary concessions during the Festival. Because of the cost of installing additional supply over the cliffs, generators have to be used.

The cliff line is cut by steep gullies or chines, eroded by small streams after the Ice Age, but only the largest still has a water course, which is the Bourne Stream, which gave the town its name (Clifford \& King, 2006). The Chines are advantageous as they offer several access points to the beach and importantly Durley Chine also provides an additional evacuation point through from the beach to the west of the Pier, to the clifftop leaving the Pier Approach area available for Emergency vehicle access (HO). This highlights that there are positive as well as negative effects of the natural environment on the Festival design.

In addition to the Chines, several paths zigzag up from the undercliffs to the over cliff, together with two cliff lifts (Funicular railways) built either side of the Pier in 1908 (Visit Bournemouth, 2020). Unfortunately, during the 2016 Festival, the East Cliff Lift was out of action due to a significant cliff slide. Along the cliff top are areas of maritime and dune grassland. As Flightline UK (2011) noted: 
The seafront at Bournemouth does make for a unique viewing experience. As with most seafront airshows, the beaches offer the closest vantage points to the flying displays as well as an arena area. However immediately behind the beaches are the cliffs which off vantage points $150 \mathrm{ft}$ up allowing spectators to almost look down on some of the flying displays.

It also provides good views and communications for the organizers and Bronze Command (Operational level) is on the East Cliff, together with the Media Centre. Mobile phone communications can be problematic at a promenade level because of the cliffs, so the clifftop position is advantageous because real-time social media is invaluable in communicating with Festival visitors (Williams et al., 2015), updating them on any changes to the program due to the weather for example, as discussed above, as well as managing crowd control and other operational issues. The clifftop position is also used to store rubbish and recycling bins and to locate the emergency treatment center because of the problems of ingress and egress on the promenade discussed earlier and a communications mast is sited there because of the clearer signal.

Across the road from the sea are the Victorian hotels, which made the resort grow so quickly. For the Cottonwood Boutique Hotel, it is the busiest event of the year, involving considerable preplanning, which is exacerbated as their operations are affected by Festival road closures at the front and rear of the hotel. The natural environment is part of the operation in a very different way, as one of the key tasks that is carried out prior to the Festival is the pruning of the hedges on the front boundary to ensure good visibility of the event for their guests from the ground floor public rooms.

\section{Inland}

Inland from the cliffs are the Lower Pleasure Gardens, a public space that is the venue for a contrasting range of Festival activities. For example, there has been children's entertainment including street performers, circus workshops, and face painting and in 2010 The Royal Marines Combat Display team demonstrated close-quarters combat skills. Further inland, other public land such as Redhill Park provide space for a "Park and
Ride" facility on the Friday, Saturday, and Sunday of each Festival, but the financial success of this facility is again very sensitive to weather conditions (BAFD). In 2011, when an RAF Red Arrow pilot was killed as his airplane crashed (BBC News, 2011), the natural environment in a rural area on the northern edge of Bournemouth prevented a much greater tragedy than had he landed closer to the Festival site in a built-up area. This was subsequently illustrated in 2015 , when 11 people were killed after a Hawker Hunter single seat jet plane from the Shoreham Airshow (also in southern UK) crashed onto queuing traffic on a main road close by (BBC News, 2015). This accident caused the Civil Aviation Authority to impose several new rules on air shows, including that "planes are now required to be $450 \mathrm{~m}$ away from the crowds at all times." This has been facilitated relatively easily at the Bournemouth Air Festival because of its location adjacent to the sea.

Organizers have increased the Maritime Safety Zone - the area of clear water under the display area by extending it $300 \mathrm{~m}$ out to sea. It has also been expanded one groyne to the west of Bournemouth Pier and two groynes to the east of Boscombe Pier. That means the fast jet display line is now set at $230 \mathrm{~m}$ from the end of Bournemouth Pier, $130 \mathrm{~m}$ further south than last year. (Daily Echo, 2016b)

\section{Discussion}

This case study has sought to ascertain how the socionatural environment is an agent in the design and operation of the Bournemouth Air Festival. As previously discussed (Easterby-Smith et al., 2008), the BAF case is expressive in having some unique features, but also instrumental in that some general principles can be developed. Therefore, it has sought to enhance the argument for consideration of the natural environment as a prerequisite to the design and operation of an event. The factors influencing the BAF are illustrated in a conceptual framework (see Fig. 2) and have implications for the management of outdoor events in particular, but also to a lesser degree, indoor events. Organizers of events and festivals now have a means of considering the variations in the natural environment of their location and developing appropriate plans to ensure event success. 


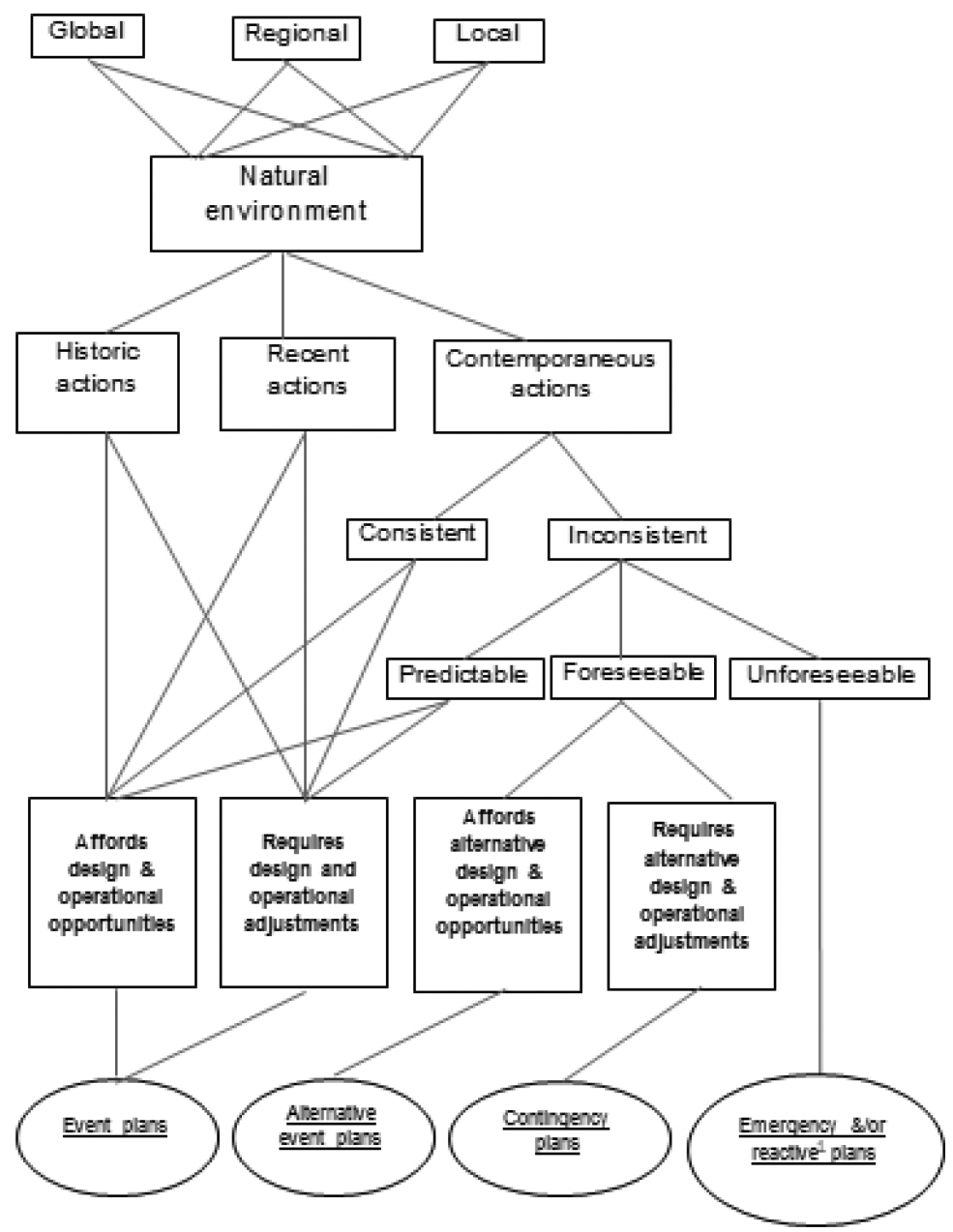

Figure 2. The variability of the natural environment and the impact on event planning.

As the framework demonstrates, the impacts of the environment can first be spatially at a global, regional, or local level. Much variation is geographically determined (e.g., the miniscule variation in gravity around the world). Similarly, the movements of the sun and earth produce differing daylight hours globally; the climate affects the event at a regional level and the weather, locally. Secondly, impacts can have a temporal element and be a result of actions that have occurred in earlier geological epochs; for example, the rare Double Tides in Poole Bay. Nature's agency also devolves from other events that have happened in the historic past (e.g., the Chines that cut through the cliffs, which provide access to the beach to both visitors and the emergency and other services). Events in the more recent past (such as the cliff fall, which provides the benefits of a passing place for fence storage) can similarly be incorporated.

Therefore, these actions afford both design and operational opportunities that can be included in the Festival planning and/or adjustments to the plans. Actions, which occur contemporaneously with the Festival, demand more complex planning. However, the first type, actions that are consistent, are less problematic and like the actions in the recent past can be incorporated into the plans. The second type, those that are inconsistent actions, are more problematic and need to be considered in three ways. 
The first group are some of nature's actions, which although inconsistent, can with the aid of scientific knowledge be predictable; for example, the times of sun rise and sunset. Predictable variation can afford opportunities for innovative elements to an event (such as the BAF night program) and the design and operation of an event can incorporate actions to counteract negative elements. The second group may not be predictable at the planning stage, but if there is a reasonable likelihood of their occurring, such as low cloud cover, contingency plans (Mallen, 2017) can be put in place, in anticipation that they might occur. The third and final group are actions that are unforeseeable; for example, when multiple actions occur together, and last-minute actions then have to be taken by organizers and for these types of actions, emergency or reactive plans are instigated (Silvers, 2012). Finally, it should be recognized that with recurring events, such as the BAF, planning can be developed year on year, so that actions by the natural environment that occur one year can lead to enhancements of the planning for subsequent years; for example, the adaption of the program to avoid the accumulation of small boats trying to enter Poole Harbor at the same time.

\section{Conclusions}

This has been the first study of its kind to consider how the agency of the natural environment has an impact on an events design and operations. As with all studies, this one has limitations. Although data were collected over several years in which the Festival has been organized, participant observation could only be undertaken on limited occasions and therefore secondary data sources, especially local media have had to be incorporated. Secondly, the Festival has always been held at the same time of year in a location that has been developed to support tourists (Salem et al., 2014) and therefore future research could consider locations in other parts of the world, where different environmental conditions exist. Similarly, locations that do not have the same experience of managing visitors would provide a valuable perspective. Therefore, testing of the conceptual framework in these different locations would contribute to our understanding of this essential element of the event industry.
To conclude, the natural landscape of Poole Bay on the southern shores of the UK forms a natural amphitheater for the Festival, which incorporates the air, sea, and land. The design has taken advantage of numerous aspects of the natural environment, both global and local, from the different experience opportunities between night and day to the blue sky as a background for the air plane flights. Operationally, there have been both positives and negatives. This study has shown first that nature is not a static or "an inert, unproblematic backdrop" (as highlighted by Rose \& Carr, 2018, p. 5 ), instead it is constantly changing. Secondly the study has revealed the value of natural capital to an event such as the Bournemouth Air Festival and the opportunities these variations can afford. For event organizers, natural resources must be valued and managed responsibly but in order to do so, it must be recognized that the agency of the natural and socionatural environment is not constant but affords both opportunities as well as the need for long-term planning, contingency planning, and prompt decision making. Such awareness could also contribute to compliance and certification through ISO 20121 - Sustainable events or the BNQ 9700-253 standard for Responsible Event Management (in Canada). To conclude, event organizers, whether of an ecocentric or anthropocentric stance (Milfont \& Duckitt, 2010) need "to use natural capital sustainably, protecting and improving it through their dayto-day operations" (DEFRA, 2011, p. 34) as well as recognize it for the lack of consistency, that it may seem at first glance to offer.

\section{Acknowledgments}

The author would like to thank the Bournemouth Air Festival Director, the Head of Operations, Bournemouth Borough Council, and other local stakeholders for their support in undertaking this study.

\section{References}

Amsel, S. (2017). Changing seasons - The tilted Earth. http://www.exploringnature.org/db/view/ChangingSeasons-The-Tilted-Earth

BBC News. (2011). Red Arrows pilot dies in Bournemouth Air Festival Crash. http://www.bbc.co.uk/news/uk-england14602900 
BBC News. (2015). Shoreham air crash: What we know. http://www.bbc.co.uk/news/uk-34039229

BBC News. (2016). Bournemouth Air Festival day two. http://www.bbc.co.uk/news/live/uk-england-dorset37105521

Beer, S. (2018). Please come, sit and share my view. Event Management, 22, 891-902. https://doi.org/10.3727/1525 $99518 X 15378845225294$

Bernard, H. R., \& Ryan, G. W. (2010). Analyzing qualitative data: Systematic approaches. Sage Publications Ltd.

Berridge, G. (2015). Designing event experiences. In S. J. Page \& J. Connell (Eds.), The Routledge handbook of events (pp. 273-288). Routledge.

Bertella, G. (2014). Designing small-scale sport events in the countryside. International Journal of Event and Festival Management, 5(2), 132-145. https://doi.org/10.1108/ IJEFM-05-2013-0008

Bladen, C., Kennell, J., Abson, E., \& Wilde, N. (2012). Events management: An introduction. Routledge.

Brown, S., \& James, J. (2004). Event design and management: Ritual or sacrifice? In I. Yeoman, M. Robertson, J. Ali-Knight, S. Drummond, \& U. McMahon-Beattie (Eds.), Festival and events management: An international arts and culture perspective (pp. 53-64). Elsevier Butterworth-Heinemann.

Brown, S., \& Hutton, A. (2013). Developments in the realtime evaluation of audience behaviour at planned events. International Journal of Event and Festival Management, 4(1) 43-55. https://doi.org/10.1108/17582951311307502

Case, R. (2013). Events and the environment. Routledge.

Case, R. (2015). Event impacts and sustainability. In S. J. Page \& J. Connell (Eds.), The Routledge handbook of events (pp. 362-384). Routledge.

Clifford, S., \& King, A. (2006). England in particular. Hodder \& Stoughton Ltd.

Daily Echo. (2015). Grounded: Flying cancelled at Bournemouth Air Festival for the first time since 2011. http://www.bournemouthecho.co.uk/news/13616873. Grounded_flying_cancelled_at_Bournemouth_Air Festival for the first time since 2011/

Daily Echo._(2016a). Bournemouth Air Festival 2016: Day two traffic, schedule updates, weather and more. http://www. bournemouthecho.co.uk/news/14692722.Bournemouth Air Festival 2016 Day Two live/?ref=mrb\&lp=1

Daily Echo. (2016b). Safety zone extended for Bournemouth Air Festival 2016 after Shoreham crash. http://www. bournemouthecho.co.uk/news/14679982.Safety zone extended_for_Bournemouth_Air_Festival_2016_after_ Shoreham $\mathrm{crash} /$ ?ref $=\mathrm{mac}$

Department of Environment, Food and Rural Affairs. (2011). The natural choice: securing the value of nature. https:// assets.publishing.service.gov.uk/government/uploads/ system/uploads/attachment_data/file/228842/8082.pdf

Department of Environment, Food and Rural Affairs. (2014). Ecosystem services. https://www.gov.uk/guidance/eco systems-services

Easterby-Smith, M., Thorpe, R., \& Jackson, P. R. (2008). Management research (3rd ed.). Sage Publications Ltd.
Evans, G. (2015). Events, cities and the night-time economy. In S. J. Page \& J. Connell (Eds.), The Routledge handbook of events (pp. 415-430). Routledge.

Fennel, D. A., \& Nowaczek, P. (2010). Moral and empirical dimensions of human-animal interactions in ecotourism: Deepening an otherwise shallow pool of debate. Journal of Ecotourism, 9(3), 239-255. https://doi.org/ $10.1080 / 14724041003741519$

Ferdinand, N., \& Williams, N. (2015). Events staging. In S. J. Page \& J. Connell (Eds), The Routledge handbook of events (pp. 234-247). Routledge.

Flightline UK. (2011). 2011 UK Airshows: Review. http:// www.airshows.org.uk/2011/airshows/uk-airshows-2011bournemouth-air-festival-review.html

Fox, D. (2012). Urban-proximate nature as a resource for events and festivals: A SWOT analysis. 6th International Conference on Monitoring and Management of Visitors in Recreational and Protected Areas, August 21-24, Stockholm, Sweden.

Fox, D., Gouthro, M., Morakabati, Y., \& Brackstone, J. (2014). Doing events research: From theory to practice. Routledge.

Gerring, J. (2017). Case study research: Principles and practice (2nd ed.). Cambridge University Press.

Getz, D. (2002). Why festivals fail. Event Management, 7, 209-219. https://doi.org/10.3727/152599502108751604

Getz, D. (2012). Event studies: Theory, research and policy for planned events ( 2 nd ed.). Routledge.

Gibson, C., \& Connell, J. (2015). The role of festivals in drought-affected Australian Communities. Event Management, 19, 445-459. http://dx.doi.org/10.3727/15259 $9515 X 14465748512560$

Goldblatt, J. (2005). Special events: Event leadership for a new world. John Wiley \& Sons.

Google Maps. (2018). United Kingdom. https://www.google. co.uk/maps/@50.7295209,-1.674932,10.75z

Grant-Braham, B. (2013). Chairing a safety advisory group for a top ten global hallmark event. Making Waves: International Conference on Events and 10th AEME Forum, Bournemouth University, July 3-5 (pp. 289-293).

Hirt, C., Claessens, S., Fecher, T., Kuhn, M., Pail, R., \& Rexer, M. (2013). New ultrahigh-resolution picture of Earth's gravity field. Geophysical Research Letters, 40(16), 4279-4283. https://doi.org/10.1002/grl.50838

Holden, A. (2008). Environment and tourism (2nd ed.). Routledge.

Holmes, K., Hughes, M., Mair, J., \& Carlsen, J. (2015). Events and sustainability. Routledge.

Jones, B., Scott, D., \& Khaled, H. A. (2006). Implications of climate change for outdoor event planning: A case study of three special events in Canada's National Capital Region. Events Management, 10, 63-76. https://doi. org/10.3727/152599506779364615

Jones, M. (2018). Sustainable event management: A practical guide (3rd ed.). Routledge.

Kortenkamp, K. V., \& Moore, C. F. (2001). Ecocentrism and anthropocentrism: Moral reasoning about ecological commons dilemmas. Journal of Environmental 
Psychology, 21, 261-272. https://doi.org/10.1006/jevp. 2001.0205

LatitudeLongtitude.org. (2018). Bournemouth, United Kingdom latitude longitude. http://latitudelongitude.org/gb/ bournemouth/

Lock, H. O. (1948). Dorset. Adam \& Charles Black.

Mair, J. (2014). Events as proenvironmental learning spaces. Event Management, 18, 421-429. http://dx.doi.org/10. 3727/152599514X14143427352111

Mallen, C. (2017). The event operational planning phase. In C. Mallen \& L. J. Adams (Eds.), Event management in sport, recreation and tourism: theoretical and practical dimension (pp. 67-86). Routledge.

Met Office. (2017). Weather: Bournemouth. http://www. metoffice.gov.uk/public/weather/forecast/gcn8t1p3y

Met Office. (2018a). What is climate change? https://www. metoffice.gov.uk/climate-guide/climate-change

Met Office. (2018b). UK regional climates. https://www. metoffice.gov.uk/climate/uk/regional-climates/so\#wind

Met Office. (2021). UK Climate Averages. https://www. metoffice.gov.uk/research/climate/maps-and-data/ uk-climate-averages/gen 8 yhpc 1

Milfont, T. L., \& Duckitt, J. (2010). The environmental attitudes inventory: A valid and reliable measure to assess the structure of environmental attitudes. Journal of Environmental Psychology, 30, 80-94. https://doi. org/10.1016/j.jenvp.2009.09.001

Natural Capital Committee. (2019). Natural capital terminology. https://assets.publishing.service.gov.uk/government/ uploads/system/uploads/attachment_data/file/909202/nccterminology.pdf

Orefice, C. (2018). Designing for events-A new perspective on event design. International Journal of Event and Festival Management, 9(1), 20-33. https://doi.org/10.1108/ IJEFM-09-2017-0051

Page, S. J., \& Connell, J. (2009). Tourism: A modern synthesis (3rd ed.). South-Western Cengage Learning.

Pettersson, R., \& Getz, D. (2009). Event experiences in time and space. Scandinavian Journal of Tourism and Hospitality Research, 9(2/3), 308-326. https://doi.org/ $10.1080 / 15022250903119504$

Pine, B., \& Gilmore, J. H. (1999). The experience economy. Harvard.

Porter, B., \& Kaufman, M. (2013). Juggling the environment, social \& economic benefits and costs of a green environment. In T. Pernecky \& M. Luck (Eds.), Events, society and sustainability (pp. 197-210). Routledge.

Rawlings, K. (2005). Just Bournemouth. The Dovecote Press Ltd.

Rose, J., \& Carr, A. (2018). Political ecologies of leisure: A critical approach to nature-society relations in leisure studies. Annals of Leisure Research, 21(3), 265-283. https://doi.org/10.1080/11745398.2018.1428110

Ross, D. (2010). Centenary flight that resulted in untimely death of Mr Rolls. Daily Echo. http://www.bournemouthecho.co.uk/news/features/snapshotsofthepast/5062450.
Centenary_flight_that_resulted_in_untimely_death_of_ Mr_Rolls/

Royal Air Force. (2017). FAQs. https://www.raf.mod.uk/ reds/aboutus/faqs.cfm

Royal Navy. (2016). Royal Navy helps make Bournemouth Air Festival a flying success. https://www.royalnavy.mod.uk/ news-and-latest-activity/news/2016/august/23/160823rn-help-make-bournemouth-festival-a-success

Sadd, D., \& Gouthro, M. B. (2013). Events management. In J. Fletcher, A. Fyall, D. Gilbert, \& S. Wanhill (Eds.), Tourism principles \& practice (5th ed.) (pp. 372-388). Pearson Education Ltd.

Salem, G., Jones, E., \& Morgan, N. (2014). An overview of events management. In I. Yeoman, M. Robertson, J. Ali-Knight, S. Drummond, \& U. McMahon-Beattie (Eds.), Festival and events management: An international arts and culture perspective (pp. 14-31). Elsevier Butterworth-Heinemann.

Scaife, A. A. (2010). Impact of ENSO on European Climate. https://www.ecmwf.int/sites/default/files/elibrary/ 2012/12119-impact-enso-european-climate.pdf

Silvers, J. R. (2012). Professional event coordination (2nd ed.). John Wiley \& Sons Inc.

Simons, P. (2014). Weather eye. https://www.thetimes.co.uk/ article/weather-eye-paul-simons-8x8wqn $73 \mathrm{zc0}$

The Beach Guide. (2017). Bournemouth weather and tides. https://www.thebeachguide.co.uk/south-west-england/ dorset/pier-bournemouth-weather.htm

Thompson, S. C. G., \& Barton, M. A. (1994). Ecocentric and anthropocentric attitudes toward the environment. Journal of Environmental Psychology, 14(1), 149-157. https://doi.org/10.1016/S0272-4944(05)80168-9

Thornton, M., \& McGowan, J. (2010). Marine. In R. Chapman (Ed.), The natural history of Bournemouth and the surrounding area (pp. 189-207). Wessex Books.

Timeanddate.com (2017). Bournemouth, ENG, United Kingdom-Sunrise, sunset, and moon times for today. https:// www.timeanddate.com/astronomy/uk/bournemouth

Tum, J., Norton, P., \& Wright, J. N. (2006). Management of event operations. Butterworth-Heinemann.

USA Today. (2013). 10 best air shows around the world. https://eu.usatoday.com/story/travel/destinations/ 2013/02/26/10-best-air-shows-around-the-world/1947107/

Vickers, G. (1981). Some implications of systems thinking. In Open University Systems Group (Eds.), Systems behaviour (3rd ed., pp. 19-25). Harper and Row in association with the Open University Press.

Visit Bournemouth. (2020). West cliff lift. https://www.visitbournemouth.com/attractions/west-cliff-lift

Williams, N. L., Inversini, A., Buhalis, D., \& Ferdinand, N. (2015). Community crosstalk: An exploratory analysis of destination and festival eWOM on Twitter. Journal of Marketing Management, 31(9-10), 1113-1140. https:// doi.org/10.1080/0267257X.2015.1035308

Yin, R. K. (2009). Case study research: Design and methods (4th ed.). Sage Ltd. 
Copyright of Event Management is the property of Cognizant, LLC and its content may not be copied or emailed to multiple sites or posted to a listserv without the copyright holder's express written permission. However, users may print, download, or email articles for individual use. 